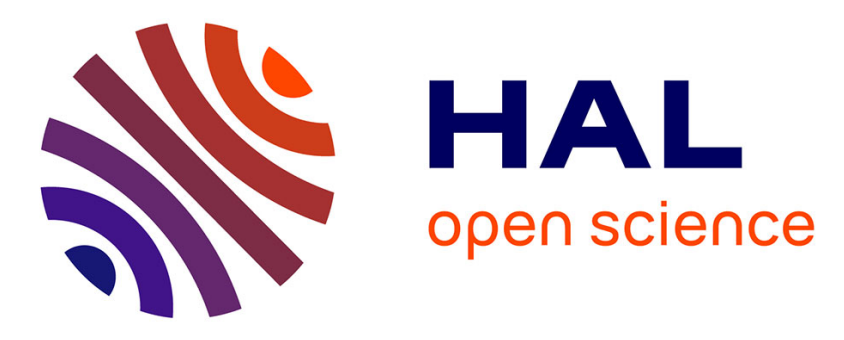

\title{
Treatment of gas containing hydrophobic VOCs by a hybrid absorption-pervaporation process: The case of toluene
}

Frederic Heymes, Peggy Manno Demoustier, Françoise Charbit, Jean-Louis Fanlo, Philippe Moulin

\section{To cite this version:}

Frederic Heymes, Peggy Manno Demoustier, Françoise Charbit, Jean-Louis Fanlo, Philippe Moulin. Treatment of gas containing hydrophobic VOCs by a hybrid absorption-pervaporation process: The case of toluene. Chemical Engineering Science, 2007, 62 (9), pp.2576 - 2589. 10.1016/j.ces.2007.02.001 . hal-01916650

\section{HAL Id: hal-01916650 \\ https://hal.science/hal-01916650}

Submitted on 8 Jun 2021

HAL is a multi-disciplinary open access archive for the deposit and dissemination of scientific research documents, whether they are published or not. The documents may come from teaching and research institutions in France or abroad, or from public or private research centers.
L'archive ouverte pluridisciplinaire HAL, est destinée au dépôt et à la diffusion de documents scientifiques de niveau recherche, publiés ou non, émanant des établissements d'enseignement et de recherche français ou étrangers, des laboratoires publics ou privés. 


\title{
Treatment of gas containing hydrophobic VOCs by a hybrid absorption-pervaporation process: The case of toluene
}

\author{
Frederic Heymes ${ }^{\mathrm{a}}$, Peggy Manno Demoustier ${ }^{\mathrm{b}}$, Françoise Charbit ${ }^{\mathrm{b}}$, Jean-Louis Fanlo ${ }^{\mathrm{a}}$, \\ Philippe Moulin ${ }^{\mathrm{b}, *}$ \\ ${ }^{\mathrm{a}}$ LGEI, Ecole des Mines d'Alès, 6 avenue de Clavières, Alès 30319, France \\ ${ }^{\mathrm{b}}$ LPPE, Université Paul Cézanne, Batiment Laennec, Hall C, Europole de l'arbois, BP 80, Aix en provence 13545, France
}

\begin{abstract}
The work focuses on a hybrid process for treating air charged with a hydrophobic volatile organic compound (VOC), coupling an absorption process with membrane pervaporation in order to reuse the absorbent. Toluene was chosen as the target VOC. Four topics were investigated: choice of the absorbent, hydrodynamics and mass transfer in a packed column, regeneration by pervaporation and finally analysis of the coupling of the two processes. In a previous study, 7 absorbents were compared with regard to experimental data (gas-liquid equilibrium constants, viscosity) and data from the literature. Di(2-ethylhexyl) adipate (DEHA) was shown to be the most suitable absorbent. In the first part of this work, experiments in a packed column showed that the viscosity of DEHA led to an increase in pressure drop, which nevertheless remained at a reasonable level. Mass transfer experiments were performed and kinetic constants $\left(K_{L} a\right)$ calculated. It was proven than washing with DEHA is highly efficient for toluene absorption. The most innovative part of the work is the regeneration of used absorbent by pervaporation. PDMS was chosen as the active membrane layer. Pervaporation flow rates of toluene were measured for the DEHA-toluene solutions corresponding to column foot concentrations. Transfer resistance is mainly controlled by the liquid boundary layer close to the membrane. The system was modelled and several interesting conclusions deduced. Solving the equations by means of a numerical method enabled calculation of the column height and membrane surface area required to treat a $10000 \mathrm{~m}^{3} \mathrm{~h}^{-1}$ gas flow charged with $5 \mathrm{~g} \mathrm{~m}^{-3}$ of toluene.
\end{abstract}

Keywords: Absorption; Chemical processes; Environment; Mass transfer; Membranes; Packed bed

\section{Introduction}

Atmospheric volatile organic compounds (VOCs) are involved in photochemical reactions creating ground-level ozone (urban smog) and entail environmental threats such as global warming, acid rain and air toxins. Although VOCs are emitted naturally, human sources are predominant in urban/industrialized areas. In order to reduce anthropic emissions, legislation such as the Clean Air Act Amendments (EPA, 1998) and EEC Directives (EEC, 1999, 2001) specify maximum concentration levels for VOC emissions into the atmosphere. When no upstream process improvement can lead

\footnotetext{
* Corresponding author. Tel.: +33442908501; fax: +33442908515.

E-mail address: philippe.moulin@univ-cezanne.fr (P. Moulin).
}

to a decrease in VOC emissions, it is necessary to set up an air treatment process. Currently, various processes are available for VOC abatement, such as thermal or catalytic oxidation, adsorption, condensation, absorption, membrane permeation and biological treatments (Le Cloirec, 1998). Evaluation and selection of an appropriate VOC abatement technology depends on the concentration and nature of the compounds, the flow rate of the vent gas and other factors such as safety or economic considerations. However, no single method can be used in all cases: most of the methods are specific in nature.

The aim of this research work is to study a hybrid process coupling an absorption tower with a membrane separation. The process flow sheet is given in Fig. 1. The loaded vent gas flows through a packed column in order to transfer the VOCs to the liquid phase. Consequently, the loaded air is purified. The liquid collected at the bottom of the column and enriched in 


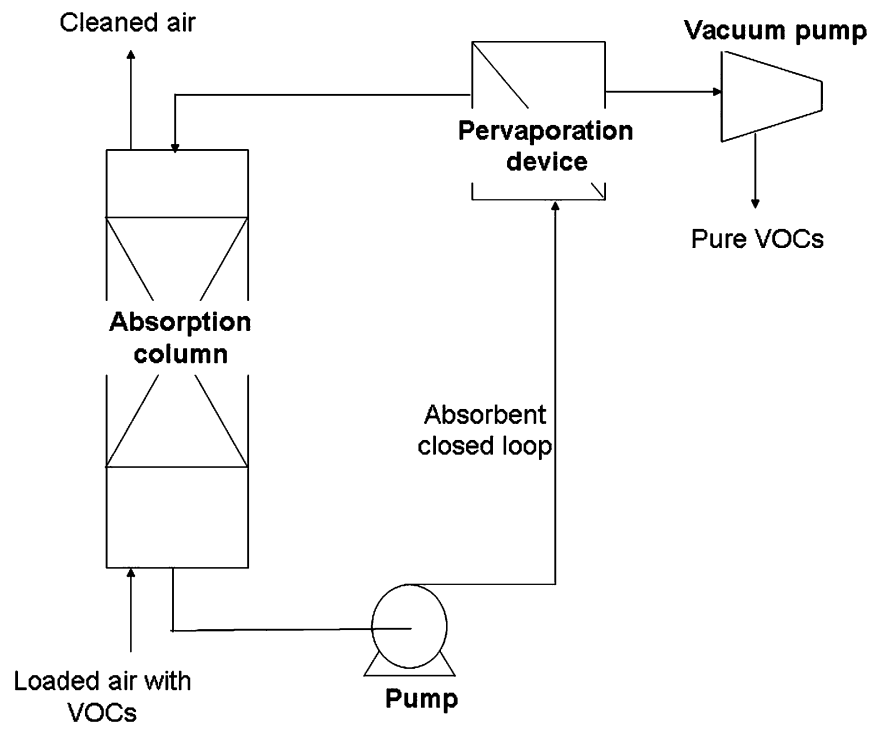

Fig. 1. Process flow sheet of the hybrid air treatment process.

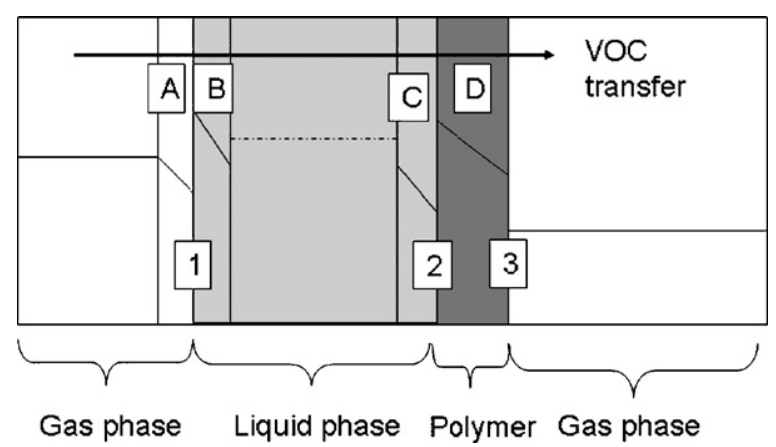

Fig. 2. Overall mass transfer system.

VOCs is pumped to the membrane device. Thanks to a vacuum pump, the VOCs are extracted from the absorbent through the membrane and the latter one can be reused in the absorber.

High-boiling organic absorbents were shown to be highly efficient to trap hydrophobic VOCs in polluted air. However, these absorbents are not used in industry because of the problem of the used absorbent. The organic absorbents may not be released in the nature nor in a water treatment unit and require a specific treatment. Since the absorbent will flow in a closed loop in the considered process, high-boiling organic absorbents can be used in the hybrid process.

The analysis of the system shows that three phases are involved: the gas phase of the exhaust air and the vacuum outlet, the liquid phase of the absorbent and a pseudosolid phase of the membrane material. However, the polymers used in pervaporation behave likely as a supplementary liquid phase than a solid porous phase. Fig. 2 represents all phases that the VOCs will have to cross. Since the process involves many phase transfers, absorption equilibriums and boundary layers will play a major role. Therefore, the following points have to be considered:

- The thermodynamic equilibriums between the VOCs and the liquid phase (1), between the liquid phase and the membrane material (2) and between the membrane material and the vacuum gas phase (3).

- The mass transfer kinetics between the air and the absorbent (A and B), between the liquid and the membrane material (C) and inside the membrane (D).

It has to be noted that contrary to the scheme in Fig. 2, the concentration into the liquid vary from point to point in the process and is not the same in the absorber and the pervaporation unit.

In this paper, we shall present the main experimental results obtained from absorption and pervaporation studies carried out in a pilot unit. Toluene was chosen because it is a common and widely used compound, highly hydrophobic. In the Discussion section we shall study the coupling of the two processes involved.

\section{Experimental results}

\subsection{Thermodynamic equilibriums}

The key point of the process is the choice of the absorbent. The aim of a previous paper (Heymes et al., 2006a) was to select the more suitable absorbent. A target hydrophobic VOC was chosen (toluene). Seven absorbents were experimentally investigated and theoretical considerations led to the selection of di(2-ethylhexyl) adipate (DEHA) as the most attractive absorbent for this study. Chemical properties of pure DEHA, pure toluene and DEHA-toluene mixtures are reported in Table 1. DEHA was chosen because (1) absorption equilibrium between gaseous toluene and liquid DEHA promotes toluene absorption, (2) vapor pressure of DEHA is very low, (3) DEHA is less viscous than other organic absorbents previously studied, (4) DEHA is currently not considered as toxic nor explosive. The equilibrium between toluene and DEHA was found to follow Henry's law:

$P=H x$

A previous investigation gave Henry's constants at different temperatures. Finally, the constant can be calculated according to the equation

$\ln H=26.925-\frac{5772}{T}$.

In dilute phase, Henry's law can be written in order to involve concentrations:

$C_{G} R T=H \frac{C_{L}}{C_{L}+\rho_{\mathrm{DEHA}} / M_{\mathrm{DEHA}}}$,

$C_{G} \approx \frac{H}{R T} \frac{M_{\mathrm{DEHA}}}{\rho_{\mathrm{DEHA}}} C_{L}=H^{\prime} C_{L}$.

This dimensionless Henry's constant $H^{\prime}$ related to concentrations will be used in modelling. Absorption of gaseous toluene 
Table 1

Selection of physicochemical properties of the system

\begin{tabular}{|c|c|c|c|c|}
\hline \multicolumn{3}{|c|}{ Pure component properties } & \multicolumn{2}{|l|}{ Binary properties } \\
\hline $\begin{array}{l}\text { Molar weight } \\
\left(\mathrm{g} \mathrm{mol}^{-1}\right)\end{array}$ & 350.8 & 92.14 & $\begin{array}{l}\text { Activity coefficient } \gamma \\
\left(25^{\circ} \mathrm{C}\right)\end{array}$ & 0.52 \\
\hline $\begin{array}{l}\text { Density }\left(25^{\circ} \mathrm{C}\right) \\
\left(\mathrm{kg} \mathrm{m}^{-3}\right)\end{array}$ & 910 & 864 & $\begin{array}{l}\text { Henry's law constant } H \\
\left(25^{\circ} \mathrm{C}\right)(\mathrm{kPa})\end{array}$ & 1.93 \\
\hline $\begin{array}{l}\text { Fusion } \\
\text { temperature }\left({ }^{\circ} \mathrm{C}\right)\end{array}$ & -76 & -95 & $\begin{array}{l}\text { Diffusion coefficient } D_{L} \\
\left(25^{\circ} \mathrm{C}\right)\left(\mathrm{m}^{2} \mathrm{~s}^{-1}\right)\end{array}$ & $8.65 \times 10^{-10}$ \\
\hline $\begin{array}{l}\text { Vaporization } \\
\text { temperature }\left({ }^{\circ} \mathrm{C}\right)\end{array}$ & 210 & 110 & Toluene-PDMS & \\
\hline $\begin{array}{l}\text { Viscosity }\left(25^{\circ} \mathrm{C}\right) \\
(\mathrm{mPas})\end{array}$ & 11.2 & & $\begin{array}{l}\text { Partition coefficient } S \\
\left(25^{\circ} \mathrm{C}\right)\end{array}$ & 1018 \\
\hline $\begin{array}{l}\text { Vapor pressure } \\
\left(20^{\circ} \mathrm{C}\right)(\mathrm{Pa})\end{array}$ & $7.48 \times 10^{-6}$ & 3804 & $\begin{array}{l}\text { Diffusion coefficient } D_{M} \\
\left(25^{\circ} \mathrm{C}\right)\left(\mathrm{m}^{2} \mathrm{~s}^{-1}\right)\end{array}$ & $1.10 \times 10^{-10}$ \\
\hline
\end{tabular}

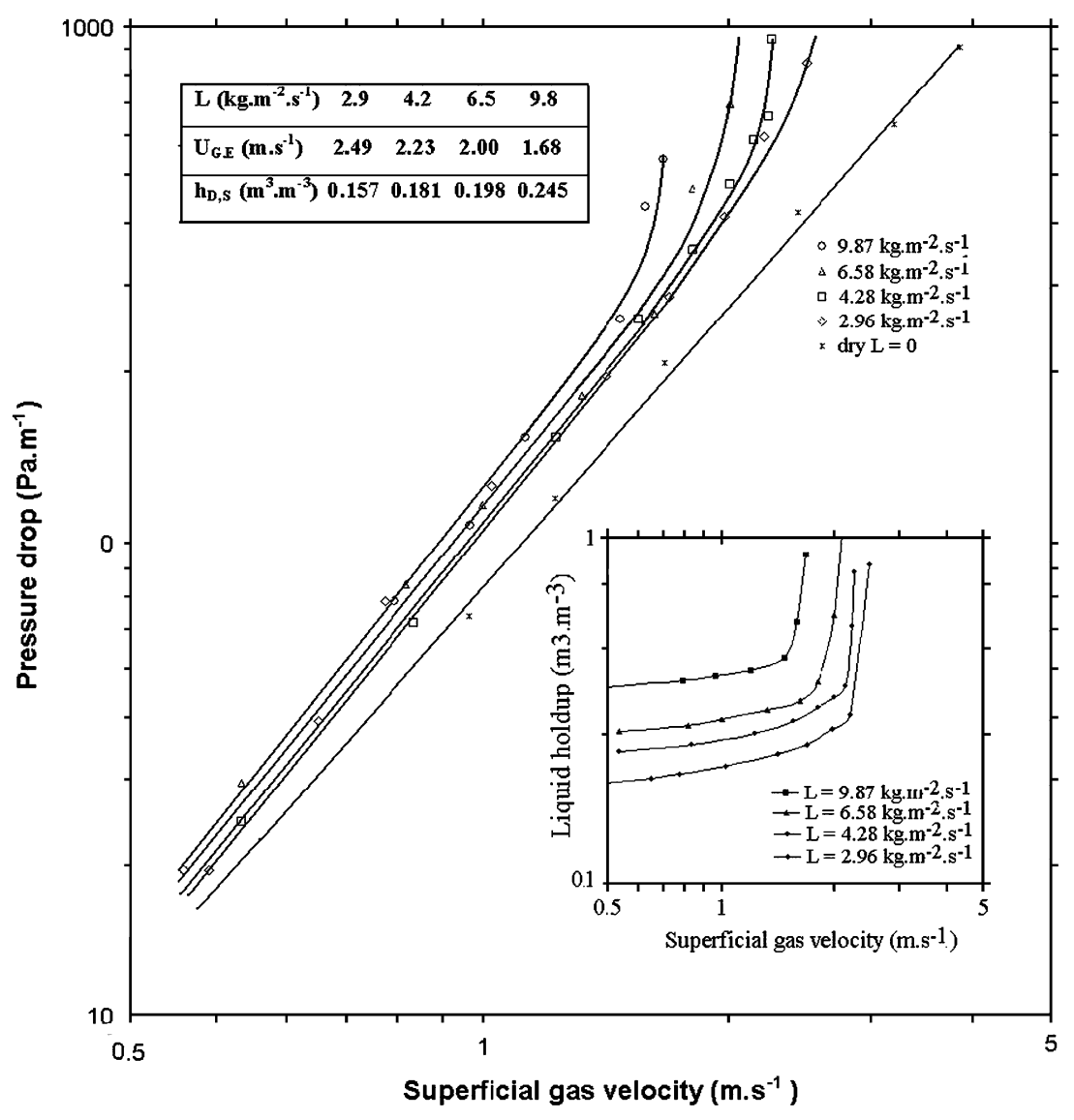

Fig. 3. Pressure drops and liquid retention in the packed column in function of gas velocity and liquid flow rate.

into polydimethyl siloxane (PDMS) was determined by De Bo et al. (2002). According to this author, the equilibrium between the gas phase and the polymer phase can be described by the law $C_{M}=S C_{G}$ with $S$ given as the following:

$\log \mathrm{S}=-0.58+0.91\left(\frac{591}{T}\right)^{2}$
The equilibrium between liquid and gas phases can be deduced from the previous data by considering a pseudogas phase. The equilibrium is represented by the equation

$C_{M} \approx S \frac{H}{R T} \frac{M_{\text {DEHA }}}{\rho_{\text {DEHA }}} C_{L}$ 


\subsection{Mass transfer in the absorber}

The aim of this section is to study hydrodynamics and mass transfer behavior in a counter-current packed column. The packed column was chosen because of low pressure drop resistance and high interfacial area. Since DEHA has a low vapor pressure, DEHA stripping should occur at a low rate.

A first point was to investigate hydrodynamic parameters (pressure drop, liquid retention) in counter-current operating mode. A second point was to study the mass transfer efficiency and kinetics of toluene absorption by DEHA flowing in a closed loop. The experimental setup is detailed in a previous paper (Heymes et al., 2006b). The experimental conditions were chosen as follows:

- air temperature between 22 and $31^{\circ} \mathrm{C}$,

- toluene concentrations in the gas: $500 ; 1000 ; 5000 \mathrm{mg} \mathrm{m}^{-3}$,

- liquid flow rates: $2.96,4.28,6.58,9.87,13.16 \mathrm{~kg} \mathrm{~m}^{-2} \mathrm{~s}^{-1}$,

- gas velocities: [0.5-5 $\mathrm{m} \mathrm{s}^{-1}$ ].

These data were chosen according to industrial concerns (Le Cloirec, 1998). The wet column pressure drop and liquid retention were measured at constant liquid flow rate, increasing the gas flow incrementally. Any sudden increase in the gas flow perturbs the system, which then gradually returns to a state of hydrodynamic equilibrium in which liquid retention and pressure drop are constant. All the results presented below were therefore measured after stabilization of the system. The plots of the pressure drop and liquid retention curves, at constant liquid flow, are shown in Fig. 3. Pressure drop [A] and liquid hold-up $[\mathrm{B}]$ are given in $\log -\log$ scale. Flooding data were determined and are reported in the chart $[\mathrm{C}]$. Concerning liquid hold-up, the resulting curves correspond to the classical behavior as described in the literature. Concerning modelling pressure drop and liquid retention, Mackowiak (1990, 1991) and Billet's formulae are sufficiently precise and can be used in order to set up an industrial absorption column (Heymes et al., 2006b).

Fig. 4 shows the experimental results for toluene recovery performance with three different gas flow rates. The toluene recovery performance is defined as the ratio of outlet toluene concentration abatement on the inlet toluene concentration. Hundred percent means a complete absorption. It appears that the ranges of flow rates and concentrations investigated give an initial toluene removal performance close to $100 \%$, whatever the configuration. This confirms the interest of DEHA as an efficient absorbent for treating a gas loaded with toluene, with concentrations varying between 500 and $5000 \mathrm{mg} \mathrm{m}^{-3}$. It is obvious to note that the removal performance decreases continuously because of the absorbent enrichment with toluene, justifying the regeneration of the absorbent.

Mass transfer constants $K_{L} a$ and $K_{G} a$ are required to design an absorption tower. Values were calculated from experimental data and are reported in Table 2. Considering experimental data, it appears that $K_{L} a$ varies considerably depending on the hydrodynamics. A difference of a factor by 10 is observed by comparing $K_{L} a$ inside and below the loading zone (Heymes et al., 2006b). This confirms the interest to operate in the loading zone.

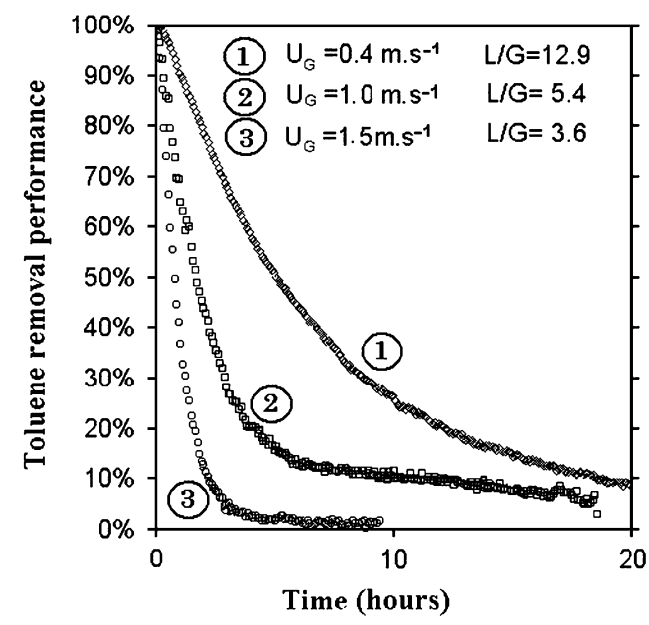

Fig. 4. Influence of gas velocity on efficiency curves in function of time $\left(L=6.58 \mathrm{~kg} \mathrm{~s}^{-1} \mathrm{~m}^{-2}\right)$.

Table 2

Experimental results of mass transfer in the packed column

\begin{tabular}{llllll}
\hline $\begin{array}{l}\text { Experiment } \\
\text { number }\end{array}$ & $\begin{array}{l}\text { [Toluene] } \\
\left(\mathrm{mg} \mathrm{m}^{-3}\right)\end{array}$ & $\begin{array}{l}L \\
\left(\mathrm{~kg} \mathrm{~m}^{-2} \mathrm{~s}^{-1}\right)\end{array}$ & $\begin{array}{l}G \\
\left(\mathrm{~kg} \mathrm{~m}^{-2} \mathrm{~s}^{-1}\right)\end{array}$ & $\begin{array}{l}K_{L} a \\
\left(\mathrm{~s}^{-1}\right)\end{array}$ & $\begin{array}{l}K_{G} a \\
\left(\mathrm{~s}^{-1}\right)\end{array}$ \\
\hline 1 & 4990 & 13.16 & 0.51 & $2.52 \times 10^{-4}$ & 2.75 \\
2 & 1205 & 13.16 & 0.51 & $2.51 \times 10^{-4}$ & 0.79 \\
3 & 1193 & 9.87 & 0.51 & $3.69 \times 10^{-4}$ & 1.89 \\
4 & 5038 & 6.58 & 0.51 & $3.23 \times 10^{-4}$ & 1.34 \\
5 & 520 & 6.58 & 1.16 & $2.28 \times 10^{-3}$ & 13.5 \\
6 & 1005 & 6.58 & 1.21 & $2.38 \times 10^{-3}$ & 13.8 \\
7 & 1005 & 6.58 & 1.81 & $2.43 \times 10^{-3}$ & 12.1 \\
\hline
\end{tabular}

The experimental $K_{L} a$ values can be compared with data from the literature. We observe that with the same column, packing and flow rates, DEHA $\left[K_{L} a: 2.5-27 \times 10^{4} \mathrm{~m} \mathrm{~s}^{-1}\right]$ occupies an intermediate position between PEG $400\left[K_{L} a\right.$ : $\left.1.4-5.5 \times 10^{4} \mathrm{~m} \mathrm{~s}^{-1}\right]$ and water $\left[K_{L} a: 78-83 \times 10^{4} \mathrm{~m} \mathrm{~s}^{-1}\right]$ (Heymes et al., 2006b). DEHA is thus more effective than PEG 400 for absorbing toluene. This is not surprising if we compare the Schmidt numbers usually used in mass transfer studies: $S c($ water $)=14 \times 10^{3}, S c(\mathrm{DEHA})=14 \times 10^{4}$ and $S c($ PEG400 $)=8.7 \times 10^{5}$. The Schmidt number is a determining factor to the mass transfer velocity in a liquid. We note a difference in the order of 10 between the Schmidt numbers of PEG 400 and DEHA, which reflects the greater aptitude of DEHA than PEG 400 for toluene absorption.

Correlations from two authors were tested: Onda et al. (1968) and Billet and Schultes (1993, 1999). The two authors' approaches are similar in terms of modelling. Nonetheless, the predictions of these authors differ considerably with regard to the true wetted interface area. This large difference in fact reflects the developments in packing materials that took place between 1968 and 1993. A high void fraction and improved shapes enable modern packing materials to provide much greater interface areas by means of a large number of droplets and trickles. Billet's correlation, established using more modern packing materials, therefore seems more appropriate to the 
packing used in this study. As expected, simply using the correlations of Onda et al. (1968) gives values very far from the experimental results. Billet's more recent correlation does give predictions closer to reality, but still very far from experimental values (overestimating $K_{L}$ by a factor of 10-50), which are therefore invalid for an industrial utilization.

Neither correlation from the literature is therefore satisfactory for modelling our system. There is currently a lack of knowledge concerning mass transfer in a packed column with viscous fluids. We shall therefore propose a correlation enabling the prediction of our results with a view to the industrial scaleup of an absorption column. In the framework of this study, we propose an empirical correlation. The form followed by our experimental results is

$S h_{L}=\frac{K_{L}}{a D_{L}}=\frac{a}{a_{\mathrm{wet}}} A S c_{L} R e_{G}^{B} R e_{L}^{C}$.

A statistic fitting of our data gives $A=1.67 \times 10^{-8}, B=1.70$ and $C=-0.048$. With these values, the mean relative absolute error is $13 \%$.

To conclude this absorption section, the hydrodynamic study showed that the viscosity of DEHA was not a technical obstacle to its implementation in an industrial column. The pressure drops caused remain acceptable. In case of mass transfer constants modelling, we established an empirical correlation accurate only in the investigated system. These two formulae were employed in Section 2.

\subsection{Mass transfer in the pervaporation device}

Pervaporation is a membrane-based separation process that is useful for fractionating certain difficult-to-separate liquid mixtures. The mechanism involved in the separation can obtain high separation selectivities, but with relatively low flow rates, which confines this technique to specific applications. A membrane process was chosen because thermal decomposition of heavy absorbents by distillation makes this process unwise to employ.

The chemical structures of toluene and DEHA are very different. A molar weight difference and a sharp boiling temperature difference $\left(105.6^{\circ} \mathrm{C}\right)$ between toluene and DEHA can be noticed (Table 1). The vapor pressures of toluene and DEHA are significantly different: toluene shall be easily extracted from DEHA by pervaporation. The membrane was therefore chosen to extract with a high flux toluene from the liquid phase. A literature review showed that PDMS is very permeable for toluene and is an interesting choice from an industrial point of view since it is a stable polymer, produced by a well-established film manufacture technique, and is already successfully used in industrial applications.

PDMS swells considerably on contact with organic solutions due to the solubilization of the molecules in the polymer. This induces several problems for an industrial use: the degradation of the polymer selectivity and a possible loss of the membrane integrity consequent to a non-homogenous and important swelling of the active layer of the membrane. A flat commercial
Table 3

Toluene flow measured during pervaporation of pure toluene $\left(T=48^{\circ} \mathrm{C}\right)$

\begin{tabular}{|c|c|c|}
\hline $\begin{array}{l}\text { Toluene concen- } \\
\text { tration in feed } \\
\left(\mathrm{gL}^{-1}\right)\end{array}$ & $\begin{array}{l}\text { Liquid } \\
\left(\mathrm{m} \mathrm{s}^{-1}\right)\end{array}$ & $\begin{array}{l}\text { Average pervaporation flow } \\
\text { rate }\left(\mathrm{kg} \mathrm{m}^{-2} \mathrm{~h}^{-1}\right)\end{array}$ \\
\hline 4.6 & 0.34 & 3.8 \\
\hline 4.6 & 0.60 & 5.1 \\
\hline 4.6 & 0.95 & 6.2 \\
\hline 6.3 & 0.34 & 5.0 \\
\hline 6.3 & 0.60 & 6.8 \\
\hline 6.3 & 0.95 & 8.6 \\
\hline 10.7 & 0.34 & 8.4 \\
\hline 10.7 & 0.60 & 11.1 \\
\hline 10.7 & 1.30 & 16.9 \\
\hline
\end{tabular}

PDMS membrane (PERVAP 1060) was used in order to characterize the pervaporation of toluene from DEHA mixtures.

A previous study (Heymes et al., 2006c) aimed to examine the feasibility to regenerate the used DEHA by pervaporation with a PDMS membrane (PERVAP 1060). Toluene concentrations into liquid were chosen in accordance of a real absorbent solution concentration at the bottom of the absorption column. Theoretically, the absorption tower treating an exhaust gas $\left(25^{\circ} \mathrm{C}\right)$ charged with toluene at $5 \mathrm{~g} \mathrm{~m}^{-3}$ will provide a maximum concentration of $17 \mathrm{~g} \mathrm{~L}^{-1}$ (DEHA). Since the thermodynamic equilibrium will never be reached in an absorption tower, the liquid concentration range was chosen as $\left[1-10 \mathrm{gL}^{-1}\right]$ for the experimental investigations.

The points of interest are the selectivity of the separation and the toluene flow rate extracted from the liquid mixture. Table 3 gives experimental toluene flow rates recovered in cold traps at different concentrations and liquid velocities. All experiments were performed at $48^{\circ} \mathrm{C}$. Results show that toluene can be extracted from the toluene-DEHA mixtures even at low concentrations. Infrared spectrometry of the permeates revealed no DEHA in the liquid samples.

However, flow rates were very low $\left(<20 \mathrm{~g} \mathrm{~m}^{-2} \mathrm{~h}^{-1}\right)$ and will require a large membrane area to regenerate sufficiently the absorbent. This negative conclusion is an evident weakness of the hybrid process and it was necessary to identify the reason of that low level of flow rate. Experiments led with different membrane thicknesses, different support layer and different liquid velocities proved that the main resistance to mass transfer is located in the liquid boundary layer at the membrane surface (Heymes et al., 2006c). Hydrodynamics of the liquid upstream of the membrane is the determining parameter of the separation.

The experiments of this piece of work were performed in a small laboratory device $\left(S=55 \mathrm{~cm}^{2}\right)$, designed to test different membranes but not to characterize hydrodynamics in a general manner. Therefore, an empirical correlation based on the results of this piece of work would not be valid to design an industrial pervaporation unit. Correlations from literature will be used in the modelling part.

\section{Discussion}

In this part, the experimental results and conclusions will be used in order to study the hybrid process. The classical 


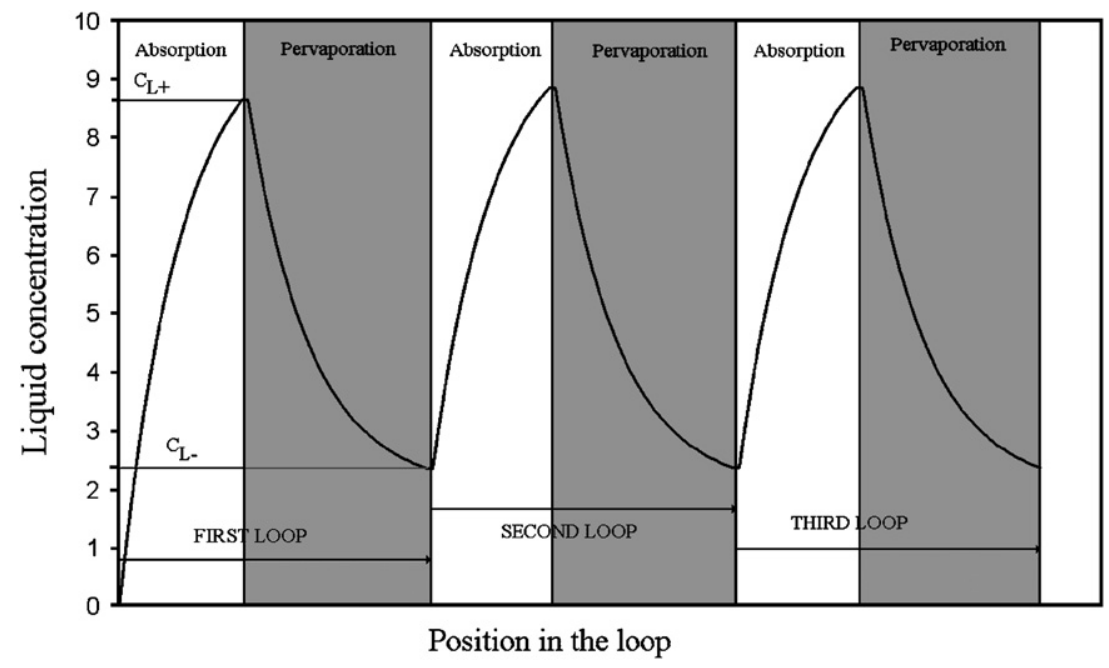

Fig. 5. Evolution of toluene concentration into the liquid during the first three loops.

equations governing the absorption are as follows:

- The mass balance:

$$
\Phi=Q_{G}\left(C_{G, \text { in }}-C_{G, \text { out }}\right)=Q_{L}\left(C_{L_{+}}-C_{L_{-}}\right) .
$$

- The mass transfer equation:

$$
\Phi=Q_{G}\left(C_{G, \text { in }}-C_{G, \text { out }}\right)=K_{L}^{\text {abs }} a V \Delta C_{L, \text { abs }}^{M L},
$$

where

$$
\Delta C_{L, \text { abs }}^{M L}=\frac{\left(C_{G, \text { in }} / H^{\prime}-C_{L_{+}}\right)-\left(C_{G, \text { out }} / H^{\prime}-C_{L_{-}}\right)}{\ln \left(\left(C_{G, \text { in }} / H^{\prime}-C_{L_{+}}\right) /\left(C_{G, \text { out }} / H^{\prime}-C_{L_{-}}\right)\right)} .
$$

The equations governing the pervaporation are:

- The mass balance:

$$
\Phi=Q_{L}\left(C_{L_{+}}-C_{L_{-}}\right) .
$$

- The mass transfer kinetics:

$$
\Phi=Q_{L}\left(C_{L_{+}}-C_{L_{-}}\right)=K_{L}^{\text {perv }} S \Delta C_{L, \text { perv }}^{M L},
$$

where

$$
\Delta C_{L, \text { perv }}^{M L}=\frac{C_{L_{+}}-C_{L_{-}}}{\ln \left(C_{L_{+}} / C_{L_{-}}\right)} .
$$

Considering all these equations, it appears that the liquid flow rate $Q_{L}$, the liquid concentrations out from the absorber $C_{L_{+}}$ and out from the membrane device $C_{L_{-}}$and the temperature (included in Henry's law constant) are coupling values.

The discussion part is divided into three parts: analysis of these coupling values on each side of the process, theoretical direct coupling as represented in Fig. 1 (the outlet of one side feeds directly the inlet of the other one) and finally pseudocoupling in the case that one at least of the three coupling values is not directly coupled between both parts of the process.

\subsection{Analysis of coupling values}

\subsubsection{Liquid concentration}

Out of the three coupling values, the pollutant concentration of the liquid is the only one which is not a directly adjustable parameter. It is the physical result of all the transfers taking place in the hybrid system. It is not constant throughout its circulation loop: it is at its maximum at the column outlet $\left(C_{L_{+}}\right)$ and minimum at the outlet of the pervaporation module $\left(C_{L_{-}}\right)$.

In the ideal case of an infinitely high column and infinite membrane surface area, we would have both thermodynamic equilibriums between the liquid phases at the column outlet and the gas phases at the column inlet, and a zero concentration of toluene in the liquid at the pervaporation module outlet:

$C_{L_{+}} \approx \frac{R T}{H} \frac{\rho_{\mathrm{DEHA}}}{M_{\mathrm{DEHA}}} C_{G, E} \quad$ and $\quad C_{L_{-}}=0$

However, the concentration $C_{L_{+}}$is lower than this equilibrium value and $C_{L_{-}}$is not zero. The values of this concentration depend on the efficiency and scaling of the apparatus used. Solving previous equations independently and successively allows drawing the concentration into the liquid loop (Fig. 5).

\subsubsection{Influence of temperature}

The temperature is a coupling value acting differently on each side of the process. From the hydrodynamics point of view, an increase of temperature will decrease the viscosity of the absorbent and increase the Reynolds number of the liquid. The boundary layer film will be thinner and the mass transfer will be increased. However, temperature will modify the thermodynamic equilibriums. Table 4 summarizes the influence of temperature on the Reynolds number, Henry's law constant $H^{\prime}$ and the air-membrane solubility $S$ in case of a flow in a tube $\left(5 \mathrm{~m} \mathrm{~s}^{-1}, 1 \mathrm{~mm}\right)$. As expected, the Reynolds number increases rapidly with the temperature. Operating at $60^{\circ} \mathrm{C}$ instead of $20^{\circ} \mathrm{C}$ will increase the Reynolds number by a factor of four 
but will decrease the solubility in the liquid by a factor of 10 and by a factor of seven in the membrane.

Because of these antagonist effects, it is not obvious to model the influence of the temperature. On the absorption process, the temperature increases the mass transfer mechanisms but decreases strongly the absorption capacity of the liquid. On the membrane process, a temperature increase will increase the mass transfer in the liquid film and through the polymer but will decrease the absorption capacity of the polymer.

Experimentally, results show that rising the temperature decreases the overall efficiency of absorption but increases the efficiency of pervaporation. The usual law proposed for the latter one is

$J=J^{0} \exp \left[-\frac{E}{R}\left(\frac{1}{T}-\frac{1}{T^{0}}\right)\right]$

with $E$ as the activation energy found to be equal to $23.024 \mathrm{~kJ} \mathrm{~mol}^{-1}$ in case of DEHA mixture enriched at $9 \mathrm{~g} \mathrm{~L}^{-1}$ of toluene (Heymes et al., 2006c). Fig. 6 shows the results calculated about an industrial case $\left(10000 \mathrm{~m}^{3} \mathrm{~h}^{-1}\right.$, toluene concentration $=5 \mathrm{~g} \mathrm{~m}^{-3}$ ). The absorption column was chosen as supplied with pure absorbent and the pervaporation unit was chosen as supplied with a $10 \mathrm{gL}^{-1}$ toluene-DEHA mixture. This figure shows that increasing the temperature up to $60^{\circ} \mathrm{C}$ will divide the absorption rate by a factor of six and will multiply the regeneration rate by a factor of three. Increasing the process efficiency by modifying the temperature will in

Table 4

Influence of temperature on Reynolds number and thermodynamic equilibriums

\begin{tabular}{lrrrrrr}
\hline Temperature $\left({ }^{\circ} \mathrm{C}\right)$ & 10 & 20 & 30 & 40 & \multicolumn{1}{c}{50} & \multicolumn{1}{c}{60} \\
\hline Reynolds number & 217 & 334 & 484 & 667 & 880 & 1118 \\
Henry's constant $H^{\prime}\left(\times 10^{6}\right)$ & 118 & 231 & 431 & 772 & 1334 & 2231 \\
Air-membrane solubility constant $S$ & 2500 & 1352 & 777 & 470 & 298 & 197 \\
\hline
\end{tabular}

all cases promote one side and harm the other side. A best temperature, ideal for the overall process, should be determined.

Fig. 6 cannot be used to calculate that ideal temperature since both processes are coupled. In the previous considerations, the liquid was considered as pure at the inlet of the absorber and enriched with $10 \mathrm{~g} \mathrm{~L}^{-1}$ at the inlet of the membrane device. This would not be the case in the coupled process and complicates the understanding of the unit. Fig. 6 shows that increasing the temperature will decrease the absorption efficiency, and consequently the liquid enrichment at the bottom of the absorber. For example, raising the temperature from 20 to $60^{\circ} \mathrm{C}$ will lower the bottom concentration from 1.4 to $0.22 \mathrm{~g} \mathrm{~L}^{-1}$. Consequently, the regeneration will be harder, and finally increasing the temperature will also reduce the pervaporation efficiency.

\subsubsection{Influence of liquid flow rate}

The liquid flow rate has a strong effect on mass transfer due to boundary layers effects and diffusion resistances. Moreover, in the packed column, the liquid flow rate has to be high enough to absorb sufficiently the toluene. This point can be checked by the absorption rate defined as $R=L / G H^{\prime}$. The higher the $R$ will be, the better the absorption will be. But the flow rates cannot vary widely in a packed column since the hydrodynamics has to be located in the loading zone conditions. It is always desirable to be situated in a domain close to $60 \%$ of flooding, since this zone corresponds to the best contact of gas and liquid (maximum interface area). Decreasing the liquid flow rate will lead below the loading zone with poor mass transfer efficiency, rising up the liquid flow rate can lead to flooding. In pervaporation, increasing the liquid flow rate will promote turbulence and increase mass transfer. Two equations were used to check this point:

- Mass transfer in the packed column (Eq. (7)):

$$
S h=\frac{K_{L}^{\mathrm{abs}}}{a D_{L}}=1.67 \times 10^{-8} \frac{a}{a_{\mathrm{wet}}} S c_{L} R e_{G}^{1.7} \operatorname{Re}_{L}^{-0.048} .
$$

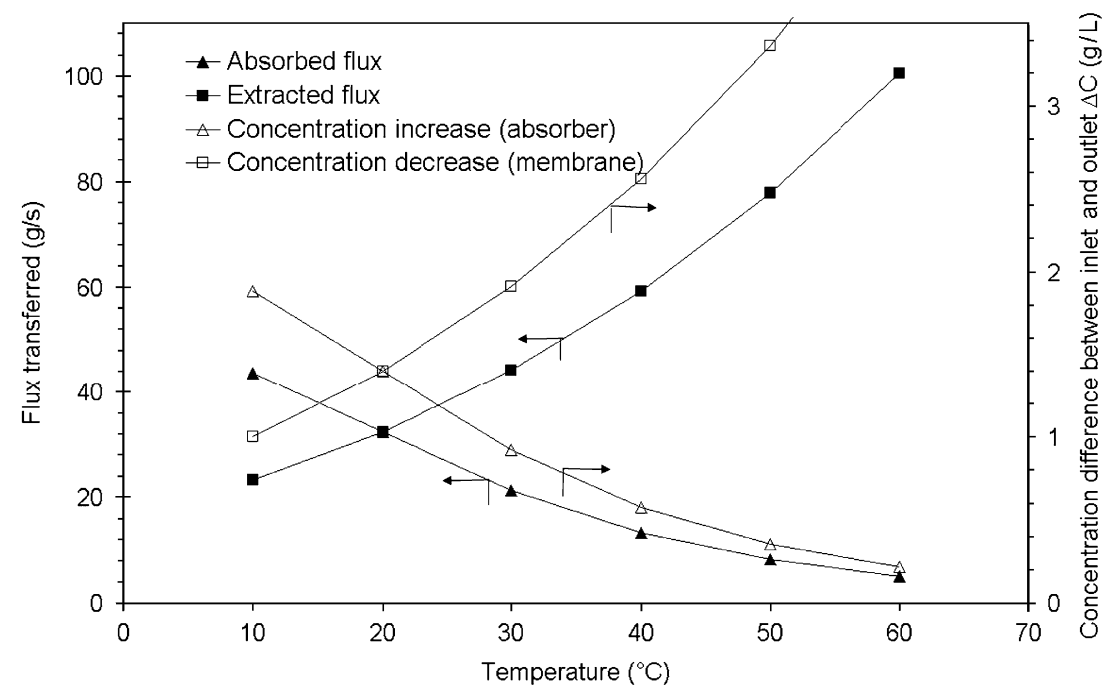

Fig. 6. Influence of temperature on the absorption and the pervaporation processes. 


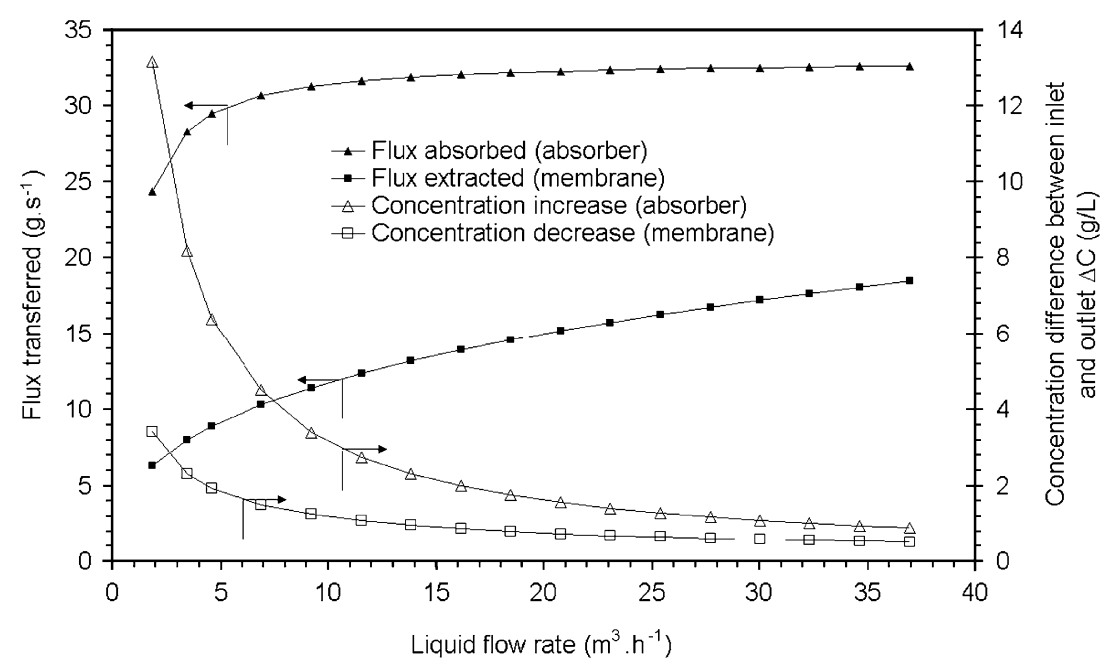

Fig. 7. Influence of temperature on the absorption and the pervaporation processes.

- Mass transfer in a tubular membrane unit (Néel, 1997):

$$
S h=\frac{K_{L}^{\text {perv }} d}{D}=1.85\left[\operatorname{ReSc}\left(\frac{d}{L}\right)\right]^{1 / 3} .
$$

Results are illustrated in Fig. 7. The black symbols represent the VOC flux absorbed in the column or extracted in the membrane device. Both fluxes increase with the liquid flow rate, what is due to higher mass transfer.

However, it should be observed that an increase in flow rate leads to a lower enrichment or regeneration of the liquid. This is shown with the white symbols in Fig. 7. At a liquid flow rate of $4.6 \mathrm{~m}^{3} \mathrm{~h}^{-1}$, the liquid is enriched with $13 \mathrm{~g} \mathrm{~L}^{-1}$ in the absorber and loses $1.9 \mathrm{~g} \mathrm{~L}^{-1}$ of toluene in the membrane device. At a higher flow rate of $30 \mathrm{~m}^{3} \mathrm{~h}^{-1}$, the liquid is enriched only with $1 \mathrm{~g} \mathrm{~L}^{-1}$ in the absorber and loses only $0.6 \mathrm{gL}^{-1}$ of toluene in the membrane device. This can be understood as a loss of transferred matter due to a lower time spent in the device. In case of the coupled process, this could play a limiting role on the overall efficiency.

In conclusion, the study of the coupling values shows that the hybrid process depends on both temperature and liquid flow, whose effects can have opposite consequences on the performance of each operation. The aim of the following section is to model the system in order to determine that optimum.

\subsection{Formulation of equations for the coupled process}

Considering the case of a continuous process such as that shown in Fig. 1, the hybrid system can be modelled from basis equations (8)-(13). The problem therefore consists in resolving the following system of equations:

$$
\left\{\begin{array}{l}
K_{L}^{\text {abs }} a V \frac{\left(\left(C_{G, \text { in }} / H^{\prime}\right)-C_{L_{+}}\right)-\left(\left(C_{G, \text { out }} / H^{\prime}\right)-C_{L_{-}}\right)}{\ln \left(\left(\left(C_{G, \text { in }} / H^{\prime}\right)-C_{L_{+}}\right) /\left(\left(C_{G, \text { out }} / H^{\prime}\right)-C_{L_{-}}\right)\right)}=Q_{G}\left(C_{G, \text { in }}-C_{G, \text { out }}\right) \\
Q_{L}\left(C_{L_{+}}-C_{L_{-}}\right)=Q_{G}\left(C_{G, \text { in }}-C_{G, \text { out }}\right) \\
\ln \left(\frac{C_{L_{+}}}{C_{L_{-}}}\right)=\frac{K_{L}^{M} S}{Q_{L}}
\end{array}\right\} .
$$

This system can be modified as the following:

$$
\left\{\begin{array}{l}
\frac{K_{L}^{\text {abs }} a V}{H^{\prime}} \frac{\left(1-H^{\prime} C_{L_{+}} / C_{G, \text { in }}\right)-\left(C_{G, \text { out }} / C_{G, \text { in }}\right)\left(1-H^{\prime} C_{L_{-}} / C_{G, \text { out }}\right)}{\ln \left(\left(C_{G, \text { in }} / C_{G, \text { out }}\right)\left(1-H^{\prime} C_{L_{+}} / C_{G, \text { in }}\right) /\left(1-H^{\prime} C_{L_{-}} / C_{G, \text { out }}\right)\right)}=Q_{G}\left(1-\frac{C_{G, \text { out }}}{C_{G, \text { in }}}\right) \\
\frac{Q_{L}}{H^{\prime}}\left(\frac{H^{\prime} C_{L_{+}}}{C_{G, \text { in }}}-\frac{C_{G, \text { out }}}{C_{G, \text { in }}} \frac{H^{\prime} C_{L_{-}}}{C_{G, \text { out }}}\right)=Q_{G}\left(1-\frac{C_{G, \text { out }}}{C_{G, \text { in }}}\right) \\
\ln \left(\frac{H^{\prime} C_{L_{+}} / C_{G, \text { in }}}{H^{\prime} C_{L_{-}} / C_{G, \text { out }}} \frac{C_{G, \text { in }}}{C_{G, \text { out }}}\right)=\frac{K_{L}^{M} S}{Q_{L}}
\end{array}\right\} .
$$


At this point we introduce the dimensionless values $X_{+}$and $X_{-}$:

$X_{+}=\frac{H^{\prime} C_{L_{+}}}{C_{G, \text { in }}} \quad$ and $\quad X_{-}=\frac{H^{\prime} C_{L_{-}}}{C_{G, \text { out }}}$.

$X_{+}$and $X_{-}$represent the ratio of the hypothetic gas concentration in equilibrium with the liquid with the real gas concentration. In all cases $X_{+}$and $X_{-}$would be as $0<X_{+}<1$ and $0<X_{-}<1$. The case $X_{+}=X_{-}=1$ corresponds to an infinite absorption column achieving thermodynamic equilibriums. Feeding the absorption column with pure liquid would lead to $X_{-}=0$. We obtain the following system:
The problem can thus be reduced to the resolution of this system of three independent equations with four dimensionless parameters. $A$ and $P$ can be rewritten as

$A=\frac{K_{L}^{\mathrm{abs}} a V C_{G}}{H^{\prime} Q_{G} C_{G}}=\frac{K_{L}^{\mathrm{abs}} a V\left(C_{L, \mathrm{eq}}^{a}-C_{L}\right)}{Q_{G} C_{G}}$ with $C_{L}=0$ (pure absorbent),

$P=\frac{K_{L}^{\text {perv }} S C_{L}}{Q_{L} C_{L}}=\frac{K_{L}^{\text {perv }} S\left(C_{L}-C_{L, \text { eq }}^{\text {perv }}\right)}{Q_{L} C_{L}}$ with $C_{L, \text { eq }}^{\text {perv }}=0$ (membrane resistance negligible).

$\left\{\begin{array}{l}\frac{K_{L}^{\mathrm{abs}} a V}{H^{\prime}} \frac{\left(1-X_{+}\right)-\left(C_{G, \text { out }} / C_{G, \text { in }}\right)\left(1-X_{-}\right)}{\ln \left(\left(C_{G, \text { in }} / C_{G, \text { out }}\right)\left(1-X_{+}\right) /\left(1-X_{-}\right)\right)}=Q_{G}\left(1-\frac{C_{G, \text { out }}}{C_{G, \text { in }}}\right) \\ \frac{Q_{L}}{H^{\prime}}\left(X_{+}-\frac{C_{G, \text { out }}}{C_{G, \text { in }}} X_{-}\right)=Q_{G}\left(1-\frac{C_{G, \text { out }}}{C_{G, \text { in }}}\right) \\ \ln \left(\frac{C_{G, \text { in }}}{C_{G, \text { out }}} \frac{X_{+}}{S X_{-}}\right)=\frac{K_{L}^{M} S}{Q_{L}}\end{array}\right\}$.

Four ratios appear:

$A=\frac{K_{L}^{\mathrm{abs}} a V}{H^{\prime} Q_{G}}$ which characterizes the absorption column,

$P=\frac{K_{L}^{\text {perv }} S}{Q_{L}}$ which characterizes the pervaporation device,

$E=\frac{C_{G, \text { out }}}{C_{G, \text { in }}}$ which characterizes the overall efficiency,

$R=\frac{Q_{L}}{H^{\prime} Q_{G}}$ which characterizes theflow rates in the system.

Finally, we obtain the system

$\left\{\begin{array}{l}A \frac{\left(1-X_{+}\right)-E\left(1-X_{-}\right)}{\ln \left(\left(1-X_{+}\right) / E\left(1-X_{-}\right)\right)}=(1-E) \\ R\left(X_{+}-E X_{-}\right)=(1-E) \\ \ln \left(\frac{X_{+}}{E X_{-}}\right)=P\end{array}\right\}$.

This system can be reorganized:

$\left\{\begin{array}{l}\frac{(1-E)}{A} \ln \left(\frac{1-X_{+}}{E\left(1-X_{-}\right)}\right)=\left(1-X_{+}\right)-E\left(1-X_{-}\right) \\ X_{+}-E X_{-}=\frac{(1-E)}{R} \\ \ln \left(\frac{X_{+}}{E X_{-}}\right)=P\end{array}\right\}$.

The smallest form of the system is

$\left\{\begin{array}{l}\ln \left(\frac{1-X_{+}}{E\left(1-X_{-}\right)}\right)=A \frac{R-1}{R} \\ X_{+}-E X_{-}=\frac{(1-E)}{R} \\ \ln \left(\frac{X_{+}}{E X_{-}}\right)=P\end{array}\right\}$.
It appears that $A$ represents the ratio of the toluene absorption flow in case of a pure absorbent (optimum flow rate) on the amount of toluene carried by the gas. The higher the $A$ is, the better the air is cleaned. Similarly, $P$ represents the ratio of the toluene removal mass transfer in case of no membrane resistance (optimum flow rate) on the amount of toluene carried by the liquid. Obviously, $A \geqslant 0$ and $P \geqslant 0$. For the gas flow to be treated, the column should be designed such that $A \gg 1$. Once the column is designed and $C_{L_{+}}$known, the membrane separator has to be designed such as $P \gg 1$. $E$ represents the overall removal percentage. $E=0$ means a total treatment of the air, $E=1$ means no absorption at all. Therefore $0 \leqslant S \leqslant 1$. $R$ is the absorption rate well known in absorption and it is recommended that $R \gg 1$.

Given that this system of independent equations contains three equations for only two unknowns, one of the parameters necessarily becomes an unknown. Any of the 4 parameters can be chosen in function of the nature of the problem:

- If, for a given column, we set a purification objective and an absorption rate value, the equations give the membrane surface area required ( $P$ becomes an unknown).

- If the column height and membrane surface area are fixed, the purification efficiency can be predicted according to the absorption rate ( $S$ becomes an unknown).

- If the column height and membrane surface area are fixed, together with a purification objective, the equations give the absorption rate to be applied ( $R$ becomes an unknown).

- Finally, if we fix a priori an absorption rate for a given purification efficiency, with a fixed membrane surface area, we can calculate the column height required ( $A$ becomes an unknown).

The solutions of the system are proposed according to the type of resolution required. The constant $K=A(R-1) / R$ is introduced to simplify the equation writing. To determine $X_{-}$, 


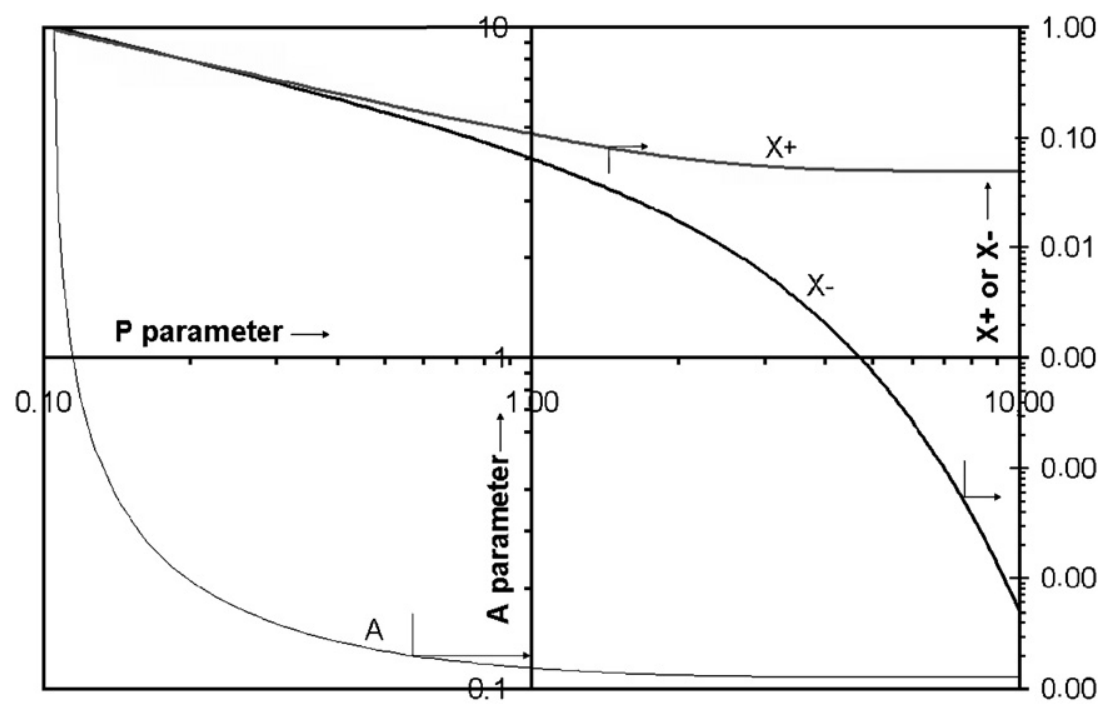

Fig. 8. Resolution of the system of equations: $A, X_{+}$and $X_{-}$vs $P$.

$X_{+}$and $P$, the resolution of the system gives the following equalities:

$$
\left\{\begin{array}{l}
X_{-}=\frac{R S K-R+1-S}{R S(K-1)} \\
X_{+}=\frac{R S \exp (K)-R+K(1-S)}{R(K-1)} \\
\ln (P)=1+\frac{[K-1](1-S)}{R(S K-1)+1-S}
\end{array}\right\} .
$$

To determine $X_{-}, X_{+}$and $A$, the resolution of the system gives the following equalities:

$$
\left\{\begin{array}{l}
X_{-}=\frac{(1-S)}{R S[\exp (P)-1]} \\
X_{+}=\frac{(1-S) \exp (P)}{R[\exp (P)-1]} \\
A=\frac{R-1}{R \ln [(\exp (P)[R-1+S]-R) /(R S \exp (P)-R S-1+S)]}
\end{array}\right\} .
$$

In the other two cases, the analytical resolution is complex and the solutions are given by a numerical resolution.

The system was solved as the example in Fig. 8. The toluene removal efficiency was taken as $E=0.9$, meaning that $90 \%$ of the initial amount of toluene will be removed from the exhaust air. An average absorption rate was chosen to be $R=2$. Fig. 8 shows on the first vertical axis the $A$ value necessary to fulfill an abatement $S$ as a function of $P$. This means that the first curve shows the necessary $K_{L} a V$ value to treat $90 \%$ of a polluted air stream as a function of the pervaporation device efficiency. This curve shows that for a deficient pervaporation unit $(P \ll 1)$, a large column is needed $(A \gg 1)$. On the other hand, if the column is not very efficient $(A \ll 1)$, a large pervaporation device will be needed $(P \gg 1)$ to fulfill the requirements. These remarks can be understood while considering $X_{+}$ and $X_{-}$values in the figure. In case of a very efficient absorption device $(A \gg 1), X_{+}$is very close to unity (absorbent quite completely saturated). The pervaporation conditions are very good and membrane device can be quite small. In the case of a very efficient pervaporation device $(P \gg 1)$, the liquid is quite completely regenerated ( $X_{-}$close to zero). A small absorption tower is required to absorb toluene with quite pure absorbent.

\subsection{Uncoupling the process}

The above points have shown that the coupling values can have opposite influences on the efficiency of either operation in the process. It may therefore be interesting to uncouple these values in an industrial process.

Temperature can be uncoupled by utilizing heat exchangers, one to cool the fluid before the column, the other to reheat it before the pervaporation module (Fig. 9). In addition, a heat recovery system could be used to optimize the global yield. In Fig. 10, we observe that the flux of toluene transferred will be maximized for each step. While the gain in terms of facility size is obvious, the cost of additional heat exchangers should nonetheless be taken into account, together with their operating costs.

The liquid flow can be uncoupled by using two additional pumps and a container to act as buffer volume (Fig. 11). By this way, the liquid flow in the column could be adjusted in function of the hydrodynamic conditions in the packing, whereas the liquid flow in the pervaporation module could remain constant. Note that the pump at the foot of the column could be eliminated if conditions enabled gravitational flow. In addition, 


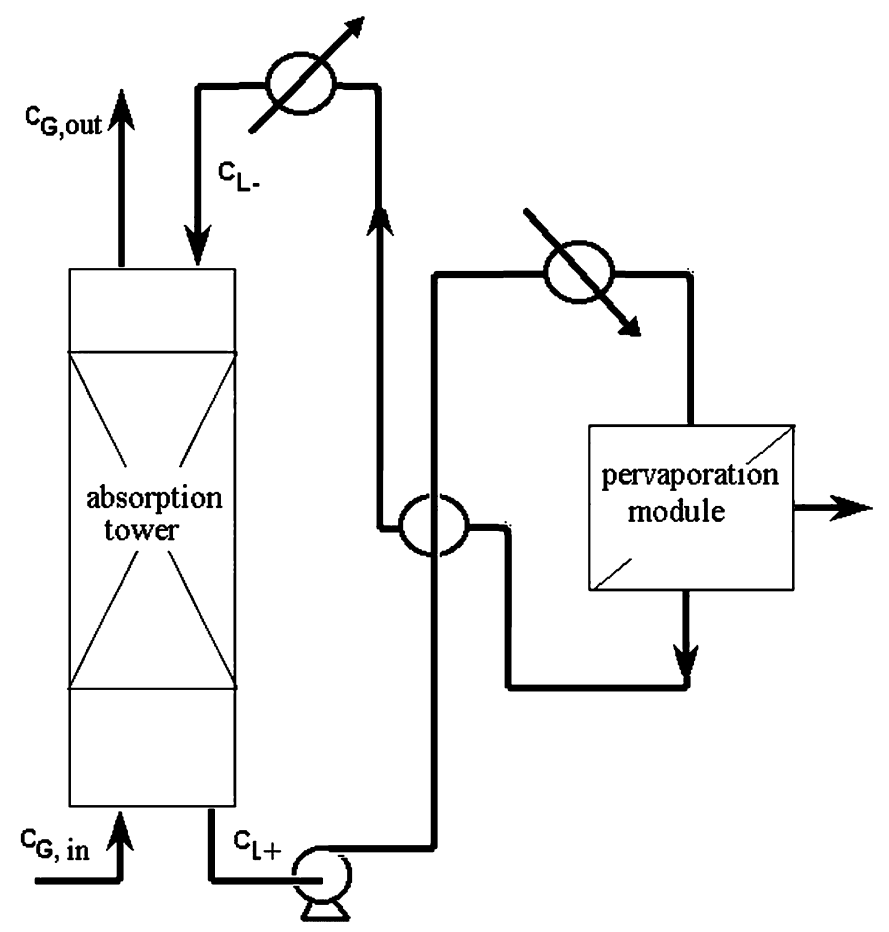

Fig. 9. Diagram of the principle of the dithermal process.

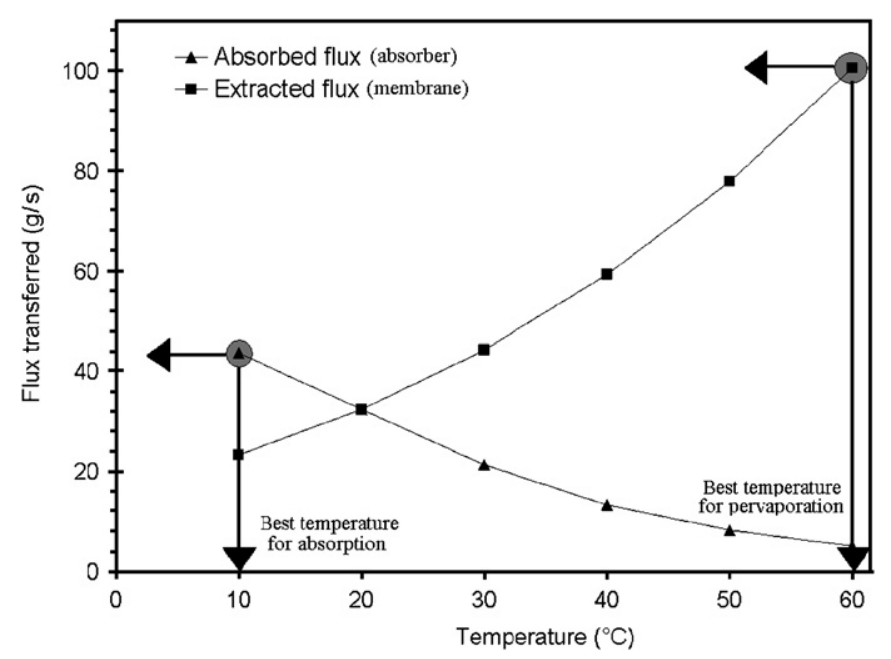

Fig. 10. Flow sheet of dithermal operation of the process.

the utilization of the buffer volume would make it possible to consider an interesting sequential operating system for the hybrid process. During stoppage of emission of gaseous effluents to be treated, the absorption column could be kept on stand-by while the pervaporation module could continue the regeneration process, in order to purify more washing liquid or regenerate it at times of lower operating costs (for example, at night). Direct uncoupling of the concentrations would occur during uncoupling of the liquid flow rates. Nonetheless, this uncoupling would not be favorable for the user. The dilution effect of the buffer volume on the overall operation would be negative. A simple mass balance equation shows that the concentration of

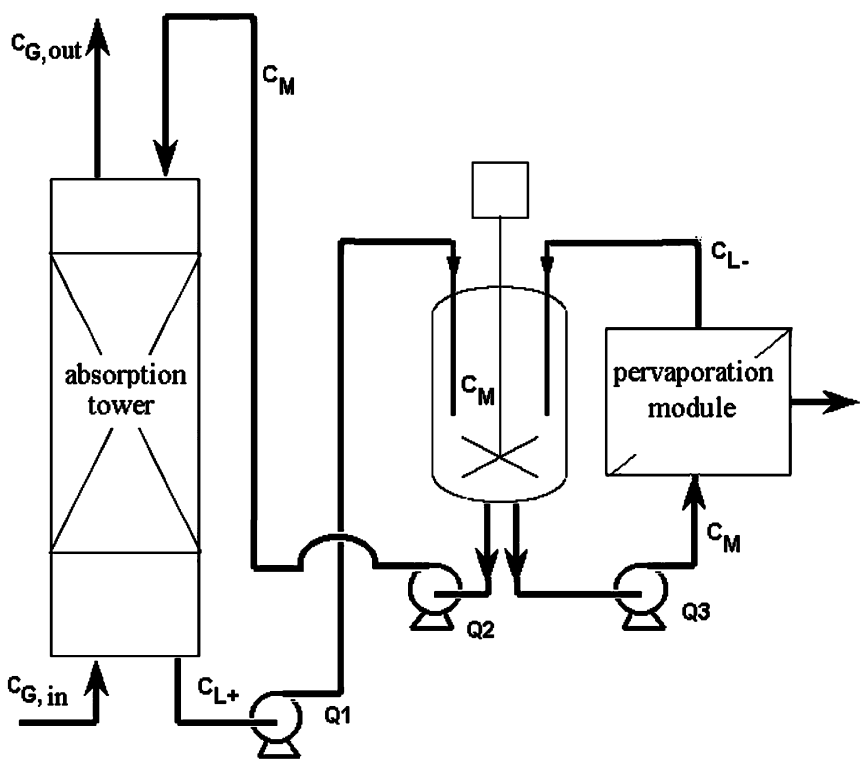

Fig. 11. Diagram of the principle of the process using a buffer container.

the buffer volume would be both lower than that at the foot of the column and higher than that of the liquid regenerated by the pervaporation module:

$$
\left\{\begin{array}{l}
Q_{1} \cdot C_{L_{+}}+Q_{3} \cdot C_{L_{-}}=Q_{3} C_{M}+Q_{2} C_{M}+\frac{\mathrm{d} V C_{M}}{\mathrm{~d} t} \\
Q_{1}+Q_{3}=Q_{2}+Q_{3}+\frac{\mathrm{d} V}{\mathrm{~d} t}
\end{array}\right\} .
$$

In the case of a permanent regime, we obtain

$$
\left\{\begin{array}{l}
C_{M}=\frac{Q_{1}}{Q_{2}+Q_{3}} C_{L_{+}}+\frac{Q_{3}}{Q_{2}+Q_{3}} C_{L_{-}} \\
Q_{1}=Q_{2}
\end{array}\right\},
$$

and thus,

$C_{M}=\frac{Q_{2}}{Q_{2}+Q_{3}} C_{L_{+}}+\frac{Q_{3}}{Q_{2}+Q_{3}} C_{L_{-}}$.

Since all the terms in this equation are positive, $C_{L_{-}} \leqslant C_{M}$ $\leqslant C_{L_{+}}$. The two facilities would therefore operate under less favorable conditions for mass transfer.

\subsection{Application: scale-up of an industrial plant}

The case of a continuous emission of toluene-loaded air will be used as the basis for the scale-up. It could, for example, be a varnishing workshop. The effluent of air to be treated was chosen to present the following specificities: gaseous flow rate $=$ $10000 \mathrm{~m}^{3} \mathrm{~h}^{-1}$, toluene concentration at factory outlet $5 \mathrm{~g} \mathrm{~m}^{-3}$ and temperature $25^{\circ} \mathrm{C}$. The constraints of the specifications are as follows: (i) in compliance with the decree regulating gaseous emissions, which fixes emission limits at $110 \mathrm{mg} \mathrm{m}^{-3}$ of total organic carbon, the maximum acceptable toluene concentration in the gas flow is fixed at $120 \mathrm{mg} \mathrm{m}^{-3}$. (ii) Since the varnishing workshop does not possess a heating utility, the process is chosen as mono-thermal. Varnishing being continuous, the utilization of a buffer tank is considered superfluous and 
the simplest version of the process is chosen. (iii) The absorption column is a packed column filled with Hiflow rings. (iv) The pervaporation process is carried out in a 1 mbar vacuum. Based on the results of this work, it was decided to use a planar pervaporation module fitted with PDMS membranes. This is a distinctly optimistic hypothesis, since industrial plants operate at downstream pressures of 100 mbar. Nonetheless, this downstream pressure of 1 mbar will be retained so as to be able to use the results of this study.

The quantity of toluene to be recovered per hour is $48800 \mathrm{~g} \mathrm{~h}^{-1}$. In order to determine the diameter of the column, we choose an arbitrary liquid flow rate $R=5$, which is a median value. For $60 \%$ flooding, the calculated column diameter is $130 \mathrm{~cm}$. The empty column gas speed would therefore be $2.09 \mathrm{~m} \mathrm{~s}^{-1}$, and the surface liquid flow from $3.03 \times 10^{-3} \mathrm{~m} \mathrm{~s}^{-1}$. With these values, the $K_{L} a$ in the column is $7.6 \times 10^{-3} \mathrm{~s}^{-1}$.

The value of the parameter $S$ is fixed at $0.0024\left(C_{G \text {,in }}=\right.$ $5 \mathrm{~g} \mathrm{~m}^{-3}$ and $\left.C_{G \text {,out }}=0.12 \mathrm{~g} \mathrm{~m}^{3}\right) . R$ is chosen as parameter, $A$ is the variable and $X_{-}, X_{+}$and $P$ are the solutions determined using the equations given above. The results are presented in Fig. 12. A good deal of information can be concluded from that figure:

- An increase in membrane surface area enables the column height to be reduced (and vice versa).

- For a given liquid flow rate, there is a membrane surface area above which any additional increase in surface area is superfluous. The process is limited by absorption.

- For a given liquid flow rate, there is a column height area above which any additional increase in column height is superfluous. The process is limited by pervaporation.

- For a given membrane surface area, the column height required for purification of the polluted effluents increases if the liquid flow rate increases.

- For a given column height, the membrane surface area required for regeneration increases if the liquid flow rate increases.

These observations are easily explained by the fact that if regeneration is very effective (high membrane surface area), then the liquid is highly depleted and the column operates under more favorable conditions, hence the lower column height required. The inverse can be explained by the fact that a high column leads to an enrichment of the liquid, which is then easier to regenerate.

Considering Fig. 12, it appears that the most economic plant to treat $10000 \mathrm{~m}^{3} \mathrm{~h}^{-1}$ of toluene enriched at $5 \mathrm{~g} \mathrm{~m}^{-3}$ should be a $3.6 \mathrm{~m}$ high column (diameter $1.3 \mathrm{~m}$ ) coupled with a $20 \mathrm{~m}^{2}$ membrane unit.

Certain hypotheses have been made that should be underlined. In the first place, it was assumed that the extrapolations of the mass transfer equations in the column and pervaporation module remain valid on the industrial scale. Next, it was assumed that the hydrodynamic behavior in the column (scaled for an absorption rate $R=5$ ) would not change when the absorption rate varied in the range [1-30], whereas flooding is likely to occur with $R$ values so far from the initial value. Fi- nally, the hypothesis of an industrial vacuum of $1 \mathrm{mbar}$ is not realistic and a value of $100 \mathrm{mbar}$ should be considered. A loss of permeate flow is to be expected. Nonetheless, the interest of this modelling study was to show the feasibility of the hybrid process. The feasible column and membrane sizes calculated in this section confirm that the hybrid process is industrially viable. Furthermore, it has been shown that there are infinite possibilities for dealing with a given problem: column size, membrane surface area, several compromises are possible. To choose the best compromise, an economic analysis is required. That is beyond the scope of this work due to lack of information. The remainder of this paper nonetheless positions the process with respect to other processes, without including any economic analysis.

\subsection{Positioning of the hybrid process: comparison with other air treatment processes}

The strengths and weaknesses of the process can be highlighted. The strengths are with respect to the limitations of other air treatment processes:

- flexibility of utilization, possibility of sequential or continuous operation,

- no by-products generated apart from pervaporates,

- relatively low temperature, therefore low risk of explosion or fire,

- possibility of operating under humid conditions,

- possible reuse of pervaporates.

Nonetheless, certain weaknesses should be presented:

- Unknown service-life of membranes, which may considerably increase the cost of the plant.

- The need to study the behavior of the membrane with each new pollutant and take into account the coupling effects.

- If dust or solid matter is present in the gas to be treated, there is risk of accumulation in the circulation loop. However, this risk can be avoided by upstream dedusting.

It should also be noted that distillation under vacuum is a possible alternative technological solution instead of pervaporation for regenerating the absorbent. If we assume that the liquid and gas phases are ideal, the equilibrium curves at constant pressure can be traced from the saturated vapor pressures. The packed column absorption experiments showed that the concentrations at the foot of the column do not exceed $20 \mathrm{gL}^{-1}$, i.e., a molar fraction of toluene of 0.083 . The minimum number of theoretical plateaux can be calculated by means of Fenske's equation. If we assume a toluene molar fraction at the head of the column greater or equal to 0.999 and an absorbent purification rate below or equal to $0.001\left(0.23 \mathrm{~g} \mathrm{~L}^{-1}\right)$, then Fenske's formula gives $N_{\min }=2.42$.

Regeneration of the DEHA by distillation would therefore be entirely feasible, provided that the DEHA is thermally stable. Preliminary heating experiments in which the DEHA was 


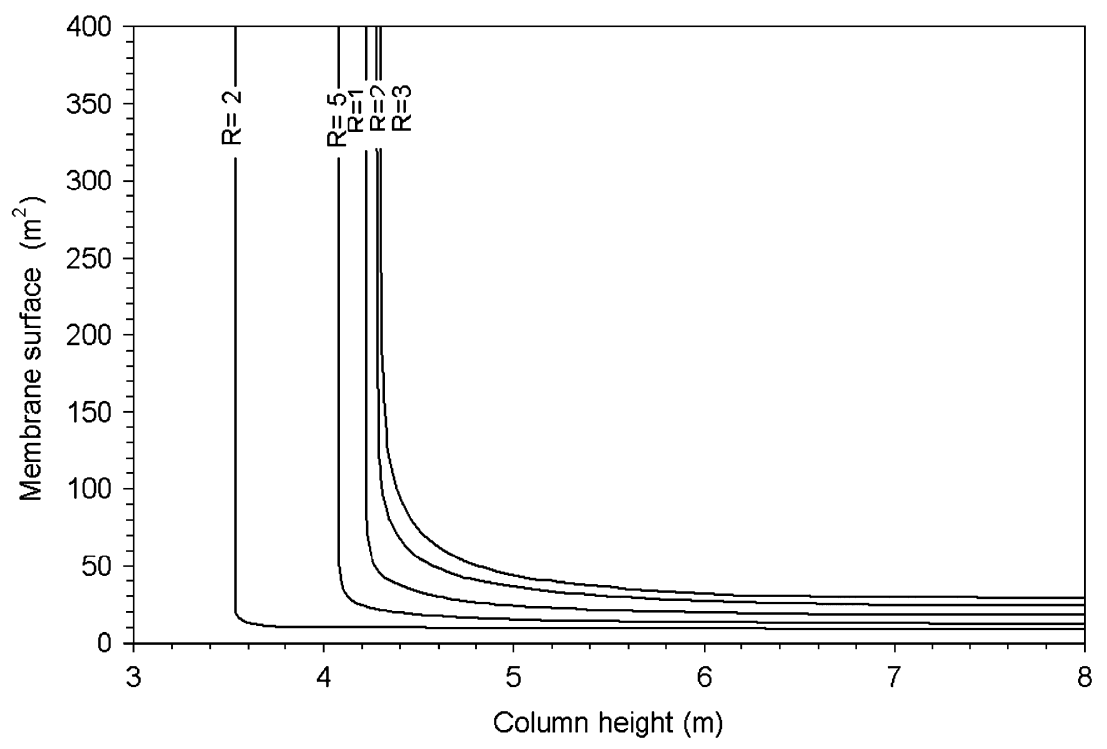

Fig. 12. Relation between column height and membrane surface area.

maintained at $100{ }^{\circ} \mathrm{C}$ for 30 days showed that the refraction index and viscosity of the DEHA were unchanged. Nonetheless, further studies at higher temperature or lower pressure are indispensable in order to decide whether distillation should be used for the regeneration process. The comparison between distillation and pervaporation requires a technical-economic analysis which is beyond the scope of this paper for reason similar to those mentioned above. Nonetheless, an essential point in the comparison is the operating mode of the plant for reasons of thermal inertia; distillation is more cost-effective in continuous operation, whereas pervaporation is potentially suited to continuous or sequential regimes.

\section{Conclusion}

VOCs are chemical species involved in the problems of atmospheric pollution. They are currently the target of regulation intended to reduce their emission levels. This measure must therefore be accompanied by the development of processes able to satisfy the new requirement in terms of emissions. This study falls within the scope of that general context. The aim of this research was to develop a treatment process for air loaded with hydrophobic compounds by coupling absorption and in situ membrane-based regeneration. The approach can be split into several steps. The first consisted in finding an absorbent likely to be suitable for an industrial application: DEHA. The second concerned the characterization and validation of the hydrophobic absorption by means of a pilot-scale apparatus. The next was devoted to studying toluene-absorbent separation using a dense membrane. Finally, the work was completed with a study of the coupling of the absorption step and regeneration by pervaporation.

DEHA was used in a pilot-scale packed absorption column. High efficiencies were observed when the column was fed with pure liquid. These efficiencies fell sharply when the absorbent became loaded with toluene, hence the need to regenerate the absorbent. The experiments showed that resistance to mass transfer was situated on the liquid side and also enabled calculation of the liquid-side mass transfer constant. It was shown that the correlations proposed in the literature do not correctly predict the experimental results, probably because of the higher viscosity of DEHA compared to the liquids used by the authors.

Organic separation by pervaporation is a subject of current importance that has given rise to many studies. Authors propose various selective membranes made of complex materials, but PDMS was finally chosen as the membrane material for separating toluene from DEHA. The influence of various operating parameters (temperature, downstream pressure, flow rate) was investigated, as were models from the literature. It was shown that the limiting phenomenon in the process is boundary layer resistance, much higher than resistance inside the membrane material. The hydrodynamics of the upstream part of the module is thus the key to the regeneration process.

The hybrid process was coupled in function of three values: flow rate, temperature and concentration. The concentration of toluene in the absorbent has a determining effect on the efficiency of the overall process. However, it is not a directly adjustable parameter, unlike temperature and flow rate. Temperature has opposite effects on the efficiency of the two steps in the process, which means either finding an optimum compromise or dithermal operation (different temperatures for the absorption column and pervaporation module). Important information was provided by formulating the equations of the system and using the correlations determined in the previous sections. It was shown that there were multiple possible membrane surface area/column height compromises for treating a given gaseous effluent. Any increase in membrane surface area can be compensated by a decrease in column height (operating at low global toluene concentrations in the liquid phase). Inversely, a high column enables a lower membrane surface area 
to be used (operating at high global toluene concentrations in the liquid phase). Calculating the initial investment and operating costs will enable the user to choose the best compromise between column height and membrane surface area.

The field of this study is vast and research has been deliberately restricted. For the absorption part, the problems of VOC absorption by viscous fluids have not been much studied in the literature. The existing correlations did not prove sufficiently accurate for predicting mass transfer constants, so additional work in this area would be useful. Similarly, the hydrodynamics of the boundary layer upstream of the membrane requires further investigation in order to determine the diffusion behavior and validate the appropriate correlations.

These two limitations are naturally also seen in the extrapolation of results obtained in the laboratory to the scale-up of an industrial unit. While it is always hard to extrapolate results obtained on a small scale to an industrial application, this is made even more difficult by the fact that the hydrodynamics of a laboratory pervaporation module is very different from those of an industrial facility. Appropriate studies are therefore indispensable in order to specify these factors. The work ended with an analysis of the coupling parameters and did not attempt an economic assessment of investment and operating costs. We consider that the scale-up results have not been sufficiently validated for costs to be estimated that would situate the project from an economic point of view.

\section{Acknowledgment}

This work was accomplished with the financial support of Agence de l'Environnement et de la Maitrise de l'Energie, (ADEME) France and the Europe Environnement Company (Vieux Thann, France).

\section{References}

Billet, R., Schultes, M., 1993. Predicting mass transfer in packed columns. Chemical Engineering Technology, 161-169.

Billet, R., Schultes, M., 1999. Prediction of mass transfer columns with dumped and arranged packings. Transactions of the IChemE 77, 498-504.

De Bo, I., et al., 2002. Application of vapour phase calibration method for determination of sorption of gases and VOC in polydimethylsiloxane membranes. Journal of Membrane Science 209, 39-52.

EEC, 1999, 2001. European Community Parliament, 1999/13/CE Directive, March 11th, 1999. 2001/81/CE Directive, October 23rd, 2001. (modified in 2001).

EPA, 1998. National Air Quality and Emissions Trends Report, USA.

Heymes, F., et al., 2006a. A new efficient absorption liquid to treat hydrophobic VOC polluted air. Chemical Engineering Journal 115, 225-231.

Heymes, F., et al., 2006b. Hydrodynamics and mass transfer in a packed column: case of toluene absorption with a viscous absorbent. Chemical Engineering Science 61, 5094-5106.

Heymes, F., et al., 2006c. Recovery of toluene from temperature boiling absorbents by pervaporation. Journal of Membrane Science 284, 145-154.

Le Cloirec, P., 1998. Les composés organiques volatils (COV) dans l'environnement. Lavoisier, Paris, France.

Mackowiak, J., 1990. Determination of flooding gas velocity and liquid hold-up at flooding in packed columns for gas/liquid systems. Chemical Engineering Technology 13, 184-196.

Mackowiak, J., 1991. Pressure drop in irrigated packed columns. Chemical Engineering Program 29, 93-105.

Néel, J., 1997. Pervaporation. Lavoisier, Paris, France. (ISBN: 2-74300213-1).

Onda, U., et al., 1968. Mass transfer coefficients between gas and liquid phases in packed columns. Journal of Chemical Engineering of Japan 1,56 . 